\title{
O PLANO DE CLASSIFICAÇÃO DE DOCUMENTOS DO CONSELHO NACIONAL DE ARQUIVOS: UMA ANÁLISE CRÍTICA
}

\section{EL PLAN DE CLASIFICACIÓN DE LOS DOCUMENTOS DEL CONSEJO NACIONAL DE ARCHIVOS: UN ANÁLISIS CRÍTICO}

Eliezer Monteiro Pinho - tc.pinho@gmail.com Arquivista na Agência Nacional de Telecomunicações (ANATEL).

\begin{abstract}
Resumo
Tendo por base o plano de classificação de documentos proposto pelo Conarq, e tomando como corte de análise a subclasse 080 - Pessoal Militar, o presente estudo traça um panorama das imprecisões e limitações do instrumento, ao mesmo tempo em que sugere novas perspectivas na aplicação da classificação enquanto função arquivística. O texto também propicia um vislumbre dos desafios de raciocínio envolvidos na prática da temática abordada, bem como sugere outra metodologia de classificação, diferente da que ora é utilizada pelo Conarq.
\end{abstract}

\section{Palavras-chave}

Recuperação da informação. Plano de classificação de documentos. Tratamento arquivístico. Gestão de documentos.

\section{INTRODUÇÃO}

A classificação é um procedimento matricial na organização dos documentos de arquivo. Todos os demais aspectos de um programa de gestão de documentos de arquivo dependem da classificação. A verificação da prescrição dos valores primários e a análise da existência do valor secundário em conjuntos documentais, por exemplo, exigem a satisfação desse pré-requisito sendo, portanto, considerados insuficientes como forma de identificação, avaliação e acesso apenas o número de registro e a data do documento (INDOLFO, 2008, p.160).

O documento, e mais tarde o arquivo, nasce no momento em que se inicia uma tarefa, um trabalho ou um registro. O plano de classificação destina-se a 
representar, sob o ponto de vista intelectual, as informações arquivísticas decorrentes do exercício de tais funções e atividades de uma organização ou pessoa física. Quanto mais a estrutura do arquivo e dos documentos que o constituem forem uma representação das suas funções, melhor e mais rápida será a recuperação da informação desejada (THOMASSEM, 2006, p. 7).

No entanto, a representação das informações contidas em documentos de arquivo como um problema para a Arquivística é recente e, por isso, ainda pouco estudada (RODRIGUES, 2003, p. 213). Segundo Ribeiro (1996, p. 9), no campo da Biblioteconomia as técnicas de tratamento documental estão suficientemente estudadas e têm uma aplicação generalizada. No campo da Arquivística, porém, as técnicas de tratamento documental não estão devidamente aprofundadas, nem as normas que existem têm aplicação consensual. p. 29):

Esta realidade é corroborada por outros autores, dentre os quais Orr (2006,

T.R. Schellenberg, arquivista norte-americano dos anos 50, manifestou a visão de que a classificação é básica para a gestão de documentos correntes. Na mesma época, na Austrália, Ian MacLean, que mais tarde iria influenciar fortemente 0 desenvolvimento da moderna arquivística australiana, escreveu que a classificação é a base do estudo da administração dos documentos modernos. No entanto, até a relativamente pouco tempo, a classificação teve quase nenhuma abordagem na literatura referente à gestão de documentos1 (Tradução nossa).

No Brasil, o desenvolvimento da classificação de documentos de arquivo se deu a partir de março de 1996, com a publicação da Resolução no 4 do Conselho Nacional de Arquivos (Conarq), a qual tornou o seu uso obrigatório nos arquivos referentes às atividades-meio da Administração Pública Federal. O plano de classificação nasceu na Secretaria de Planejamento da Presidência da República (Seplan), nos anos 80 , após a identificação de que até aquele momento não havia nenhuma iniciativa de sistematização das metodologias de tratamento dos arquivos (SOUSA et al., 2006, p. 4).

Tendo sofrido sua terceira modificação em agosto de 2004, a essência metodológica de aplicação do Plano de Classificação permaneceu inalterada. $\mathrm{O}$ estudo de Sousa e colaboradores (2006, p. 5) trazem luz acerca dos reflexos dessa trajetória, mediante algumas percepções dos usuários:

Quanto às dificuldades em aplicar o Código, a maioria (86\%) afirmou possuir dúvidas na aplicação, enquanto somente $14 \%$ não tiveram dificuldade em utilizar o instrumento. Entre as dificuldades relatadas estão: entendimento do Código (por desconhecimento e falta de clareza do instrumento), possibilidade de classificar em mais de um código (múltiplas interpretações), defasagem do Código, não contemplando todas as funções e atividades desenvolvidas pelos órgãos.

1 T.R. Schellenberg, US National Archivist in the 1950s, expressed the view that classification is basic to the management of current records. In Australia in the same year, lan MacLean, who was later to strongly influence the development of modern Australian recordkeeping, wrote that classification is the foundation of the study of modern records administration (...). However, until relatively recently, classification received scant coverage in the records management literature. 
Andresa Castro, uma das colaboradoras na elaboração do Plano de Classificação, reconhece que o instrumento tem problemas, os quais, a nosso ver, constituem motivo suficiente para a sua revisão por parte do Conarq, mediante a participação da comunidade arquivística nacional:

Andresa Castro considera um fator positivo o Código de Classificação de Documentos do Conarq possuir critérios de classificação baseados em espécies, funções, atividades e assuntos, simultaneamente. Para ela, isso não dificulta 0 entendimento, pelo contrário, dá uma abrangência maior, facilitando o trabalho do classificador. No entanto, ela considera que o Código não é autoexplicativo, é de difícil entendimento, devido às muitas técnicas e a metodologia, sendo necessário o acompanhamento de um arquivista para utilizá-lo (SOUSA et al., 2006, p. 5).

\section{AS FUNÇÕES E ATIVIDADES COMO VIAS DE SENTIDO PARA A CLASSIFICAÇÃO DE DOCUMENTOS}

As propostas de classificação do Conarq utilizam, indistintamente, nas subdivisões das subclasses, os critérios "assunto", "função", "espécie documental" ou "tipologia documental" (normalmente para apontar o assunto) e "atividade" (às vezes empregada no nível de função, ou vice-versa).

Conforme Gonçalves (1998, p. 23), o emprego do termo "assunto", no âmbito arquivístico, gera inúmeras confusões, sendo ora entendido como "atividade", ora como "tema". Seria conveniente que o uso do termo "assunto" fosse evitado, pois se refere, mais propriamente, ao conteúdo estrito de um documento. Assim, um relatório sobre as atividades de alunos e professores de uma escola municipal nas comemorações do Dia 7 de Setembro estará associado à atividade "desenvolvimento de tarefas pedagógicas" (ou outra similar), mas poderá ser remetido a "assuntos" ou temas diversos (ensino, civismo, nacionalismo, etc.).

Para melhor compreensão deste tópico, cumpre que se estabeleça o referencial teórico de distinção entre os elementos de significado aqui tratados, quais sejam:

a) Função - é o conjunto das atividades que a organização exerce para a consecução de seus objetivos. Tais atividades devem ser "similares e conexas ou interdependentes, de execução contínua e de caráter duradouro e sem término previsto" (SOUSA, 2009, p. 29).

b) Atividade - segundo a Norma Internacional para Descrição de Funções (ISDF), editada pelo Conselho Internacional de Arquivos, "atividades" são as tarefas desempenhadas por uma entidade coletiva para realizar cada uma de suas funções. Normalmente há mais de uma atividade associada a cada função.

Assim, cada função está desdobrada em atividades, que são um conjunto de procedimentos necessários para a execução de um processo de trabalho. Das atividades resultam os documentos, que são o resultado de toda essa vinculação. 
Por isso é preciso que a classificação reflita a priori as funções e as atividades do órgão que produziu ou recebeu os documentos. A tipologia documental "Folha de Respostas", por exemplo, pode estar relacionada à atividade "Exame Vestibular", que é relacionada à subfunção "Admissão de Discentes", que por sua vez está inserida na função "Graduação" (CONCEIÇÃO, 2008, p.12).

c) Espécie Documental - é a divisão de gênero documental que reúne tipos documentais por suas características comuns de estruturação da informação. São exemplos de espécies documentais ata, carta, decreto, disco, filme, fotografia, memorando, ofício (ARQUIVO NACIONAL, 2005, p. 77). Tipo ou Tipologia documental, por sua vez, é a configuração que assume uma espécie documental, de acordo com a atividade que a gerou. Por exemplo: boletim (de ocorrência, escolar, médico), certidão (de casamento, de nada consta), relatório (de atividades, de impacto ambiental). Cumpre destacar que normalmente é o tipo documental que preside a série arquivística.

Após esta rápida tomada teórica, podemos afirmar que o emprego indiscriminado de parâmetros com significado e natureza diversos tem tornado a aplicação do instrumento do Conarq bastante confusa, ainda mais quando ocorre este conflito no mesmo nível de classificação, aparecendo juntos, por exemplo, "assunto" e "atividade", "assunto" e "tipologia documental". Um breve corte da subclasse 080 (Pessoal Militar), com as devidas observações, permite melhor visualização dessa disparidade de critérios:

Código Conteúdo Observações

\begin{tabular}{|c|c|c|}
\hline 080.1 & $\begin{array}{l}\text { LEGISLAÇÃO } \\
\text { Incluem-se atos normativos internos, tais como: } \\
\text { normas, avisos, portarias (de caráter geral), bem } \\
\text { como os boletins (administrativo, de pessoal e de } \\
\text { serviço), diretrizes, procedimentos, pareceres, estudos } \\
\text { e/ou decisões de caráter geral. }\end{array}$ & LEGISLAÇÃO é assunto \\
\hline 080.2 & IDENTIFICAÇÃO MILITAR & $\begin{array}{l}\text { IDENTIFICAÇÃO } \\
\text { função2. }\end{array}$ \\
\hline 080.21 & $\begin{array}{l}\text { IDENTIDADE MILITAR. CARTEIRA. CARTÃO } \\
\text { Incluem-se documentos referentes à produção da } \\
\text { identificação militar: guia de remessa de material de } \\
\text { identificação; mapa mensal do material técnico; ficha } \\
\text { de identidade grande; ficha individual datiloscópica; } \\
\text { cartão índice; identidade provisória; ficha de dados } \\
\text { cadastrais. }\end{array}$ & $\begin{array}{l}\text { 1. Identidade Militar é tipologia } \\
\text { documental. } \\
\text { 2. Carteira e Cartão são espécies } \\
\text { documentais. }\end{array}$ \\
\hline 080.22 & $\begin{array}{l}\text { CONCESSÃO DE PASSAPORTE: DIPLOMÁTICO } \\
\text { E/OU OFICIAL }\end{array}$ & $\begin{array}{l}\text { 1. } \\
\text { CONCESSÃO }\end{array}$ DE \\
\hline 080.3 & $\begin{array}{l}\text { ASSENTAMENTOS INDIVIDUAIS. CADASTRO } \\
\text { Incluem-se folhas de alterações; caderneta registro } \\
\text { cadastro; caderneta sanitária; declaração/cadastro de } \\
\text { dependentes; declaração/alteração de beneficiários; } \\
\text { ficha de apresentação; ficha individual; ficha padrão } \\
\text { PASEP; termo de opção ou de retificação da licença } \\
\text { especial; ficha de código de especialidade e termo de }\end{array}$ & $\begin{array}{l}\text { 1. ASSENTAMENTOS } \\
\text { INDIVIDUAIS podem ser } \\
\text { assunto ou espécie } \\
\text { documental. } \\
\text { 2. CADASTRO é atividade, cujo } \\
\text { fim é manter atualizados os } \\
\text { registros funcionais dos }\end{array}$ \\
\hline
\end{tabular}

2 A função "Identificação dos militares e pensionistas da corporação" quando vista de relance pode parecer se tratar de uma atividade. Numa análise mais cuidadosa, se pode verificar que de fato é função, pois compreende atividades tais como: "Emissão de carteiras de identidade funcional", "Identificação datiloscópica dos militares e pensionistas da corporação", "Controle e destinação final de carteiras de identidade funcional no âmbito da corporação". 


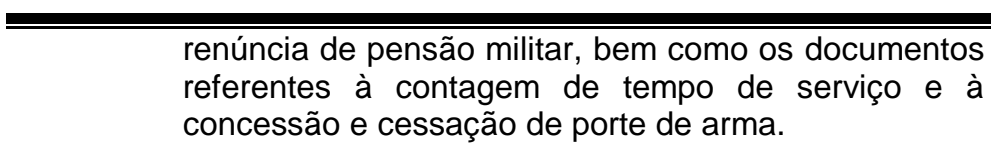

concessão e cessação de porte de arma.

servidores

organização.

3. Embora sendo atividade, este código está no nível de uma função.

\begin{tabular}{ll}
\hline \hline 081 & INGRESSO NAS FORÇAS ARMADAS \\
\hline \hline 081.1 & RECRUTAMENTO. SELEÇÃO. \\
& Incluem-se documentos produzidos em fases \\
& anteriores a incorporação: edital de concursos e \\
& orientações específicas; inscrição para concurso; \\
& questionário biográfico simplificado; seleção e \\
& designação para incorporação e matrícula; \\
& cronograma de realização de provas; material de \\
& divulgação; controle da aplicação das provas; \\
& nomeação e termo de compromisso de banca de \\
& provas; lista de candidatos; relatórios e atas dos \\
processos seletivos; provas escritas, práticas e orais \\
(exemplares únicos); gabaritos; resultados das provas; \\
relação dos candidatos aprovados; recursos; \\
instruções complementares de convocação e de \\
sistema de serviço militar; seleção para ingresso na \\
carreira militar: testes, provas de títulos, cartões \\
respostas de testes ou provas do candidato.
\end{tabular}

\subsection{INCORPORAÇÃO}

Incluem-se documentos referentes a ingresso do convocado ou voluntário, militar da reserva ou civil, em uma organização militar (OM) a qual fique vinculado de modo permanente, independente de horário, e com os encargos inerentes à referida organização: convocação à incorporação para prestar o serviço militar obrigatório, seja o serviço militar inicial ou outras formas posteriores; atos de convocação à incorporação; alistamento; dispensa ou isenção do serviço militar; estágios.

- Quanto aos atos normativos referentes ao plano geral de convocação e às instruções complementares, classificar em 080.1.

- Quanto à designação para o serviço ativo, classificar em 086.13.

\section{$081.3 \quad$ MATRÍCULA}

Incluem-se documentos referentes à admissão do convocado ou voluntário em qualquer escola, centro, curso de formação de militar da ativa, ou em órgão de formação da reserva.

\section{É assunto.}

\section{RECRUTAMENTO}

SELEÇÃO é função, pois inclui as atividades "investigação social de candida-tos", "inscrição para concurso", "controle da aplicação de provas", "designação para incorporação e matrícula", e "seleção para ingres-so na carreira militar".
1. INCORPORAÇÃO é atividade.

2. Contudo está classificada no nível de uma função.
1. MATRÍCULA é atividade.

2. Foi colocada no nível não de uma atividade, mas de uma função.

\subsection{NOMEAÇÃO}

Incluem-se documentos referentes ao ato pelo qual o convocado ou voluntário, após a sua formação e/ou preparação, ingressa nos corpos e / ou quadros de carreira de oficiais, nos postos iniciais ou nos corpos / quadros de oficiais da reserva.

\subsection{EXERCíCIOS DE MOBILIZAÇÃO /APRESENTAÇÃO} Incluem-se documentos referentes às campanhas de convocação; mapas de encargos de mobilização; relatórios sobre o exercício de apresentação da reserva; controle de efetivo de militares temporários (médicos, farmacêuticos, dentistas, veterinários); tiros de guerra.

\section{NOMEAÇÃO é atividade.}

2. Contudo está colocada no nível de uma função. 


\begin{tabular}{|c|c|c|}
\hline 081.9 & $\begin{array}{l}\text { OUTROS ASSUNTOS REFERENTES A INGRESSO } \\
\text { NAS FORÇAS ARMADAS }\end{array}$ & $\begin{array}{l}\text { O uso de "outros" e "miscelâneas" é } \\
\text { ruim na classificação de } \\
\text { documentos de arquivo. }\end{array}$ \\
\hline 082 & PLANO DE CARREIRA & $\begin{array}{l}\text { PLANO DE CARREIRA é tipologia } \\
\text { documental, aqui empregada como } \\
\text { assunto. }\end{array}$ \\
\hline 082.1 & $\begin{array}{l}\text { PROMOÇÃO } \\
\text { Incluem-se documentos referentes aos trabalhos das } \\
\text { Comissões de Promoção, tais como: contagem de } \\
\text { antigüidade; propostas de posicionamento no quadro } \\
\text { de acesso; faixa de cogitação; cogitação /inclusão no } \\
\text { quadro de acesso; lista de escolha; ato de promoção; } \\
\text { ressarcimento e reconsideração de ato; recontagem } \\
\text { de pontos; correção de posição hierárquica; retificação } \\
\text { de promoção; lista de méritos relativos; informações } \\
\text { sobre a existência de inquéritos e ações judiciais } \\
\text { envolvendo os avaliados; promoção post-mortem e } \\
\text { por motivo de justiça. }\end{array}$ & $\begin{array}{l}\text { PROMOÇÃO é função, pois abarca } \\
\text { as atividades "aplicação de cota } \\
\text { compulsória", "instrução de } \\
\text { processos de promoção", } \\
\text { "organização de quadros de } \\
\text { acesso", "assessoramento à CPO3 } \\
\text { e CPP4", "elaboração e proposição } \\
\text { de propostas de redução de } \\
\text { interstício", dentre outras. }\end{array}$ \\
\hline 082.2 & $\begin{array}{l}\text { CURSOS } \\
\text { Incluem-se documentos referentes à habilitação do } \\
\text { militar para a promoção. }\end{array}$ & $\begin{array}{l}\text { 1. A palavra CURSOS está } \\
\text { colocada aqui como assunto. } \\
\text { 2. Seu enunciado é próprio de uma } \\
\text { série documental5 relativa à } \\
\text { atividade "Instrução de Processos } \\
\text { de Promoção", contudo figura } \\
\text { como uma função. }\end{array}$ \\
\hline 082.21 & $\begin{array}{l}\text { FORMAÇÃO. ADAPTAÇÃO } \\
\text { Incluem-se documentos referentes à designação, } \\
\text { matrícula, conclusão, cancelamento, trancamento e/ou } \\
\text { desligamento dos cursos. }\end{array}$ & $\begin{array}{l}\text { 1. Este nível, bem como os outros } \\
\text { três abaixo, são subséries do } \\
\text { anterior }(082.2) \text {. } \\
\text { 2. Ambos foram classificados como } \\
\text { se fora uma atividade. }\end{array}$ \\
\hline 082.22 & $\begin{array}{l}\text { APERFEIÇOAMENTO. ESPECIALIZAÇÃO } \\
\text { Incluem-se documentos referentes à designação, } \\
\text { matrícula, conclusão, cancelamento, trancamento e/ou } \\
\text { desligamento dos cursos. }\end{array}$ & Idem \\
\hline
\end{tabular}

A utilização do critério "assunto" na classificação de documentos, de acordo com Schellenberg (2005, p. 92), vai ocorrer apenas em relação ao material não arquivístico, isto é, quando a informação for não-orgânica. Tais documentos não provêm da ação governamental positiva ou não estão a ela vinculados, mas podem ser importantes como fontes de informação para pesquisa, referência e similares.

Como pressuposto fundamental, podemos entender que a classificação de documentos de arquivo é, antes de tudo, lógica. Schellenberg (2005) aborda este importante aspecto, e deixa evidente que é na hierarquia dos níveis de classificação que o Plano de Classificação de Documentos se impõe como instrumento e esquema útil à gestão de documentos, no tocante a remetê-los ao vínculo de sentido com o seu contexto de produção e acumulação.

\footnotetext{
3 CPO - Comissão de Promoção de Oficiais.

4 CPP - Comissão de Promoção de Praças.

5 Série Documental, conforme o Dicionário Brasileiro de Terminologia Arquivística, é o conjunto de documentos relativos à mesma função, atividade, tipo documental ou assunto.
} 
É importante que haja consistência quanto aos sucessivos níveis de subdivisão de um sistema de classificação. Assim, se a subdivisão primária é pelas funções, todos os cabeçalhos neste nível devem ser funções; se a divisão secundária é por atividades, todos os cabeçalhos naquele nível devem corresponder a atividades (SCHELLENBERG, 2005, p.96).

Sousa (2006, p. 130) corrobora este aspecto doutrinário e, ao mesmo tempo, assinala outra vertente do problema - a lacuna de significado:

Uma das principais dificuldades que os arquivistas encontram não é a multiplicidade de termos utilizados para designar os níveis de classificação, mas a falta de consenso sobre o significado desses termos. As palavras categoria, classe, divisão e subdivisão por um lado, e série, subsérie (...) de doutro, dizem respeito, muitas vezes, a realidades diferentes. (...) Trabalha-se com classificação esvaziando-a dos elementos de representação que ela encerra.

\section{O RIGOR INTELECTUAL ENVOLVIDO NA ELABORAÇÃO DO INSTRUMENTO DE CLASSIFICAÇÃO DE DOCUMENTOS DE ARQUIVO}

Uma vez que as tipologias documentais se consubstanciam quando precisadas as atividades que geraram os documentos, estas se tornam de pouco valor se compreendidas fora da classificação. Isto porque só o plano de classificação pode thes conferir o sentido necessário do seu uso (LOPES, 1996, p. 95). Assim, não há como se conceber a idéia de séries documentais genéricas, pois sempre serão o resultado natural da função e atividade que lhes deram causa.

Lopez (1999, p. 21), ao afirmar que o estabelecimento de tipologias documentais se impõe como tarefa de importância premente para a gestão de documentos, também nos permite um vislumbre do rigor intelectual envolvido no trabalho de se estabelecer a adequada relação de vínculo entre a série documental e a respectiva função e atividade:

Um panfleto eleitoral - que representa o candidato e suas idéias, o partido e seu programa e no final pede o voto do eleitor - estava sendo relacionado à função de "angariar votos para eleição", enquanto por outro seria associado a "agitação e propaganda". Para solucionar o problema dessa dupla função, passei a distinguir "objetivo" de "função". O primeiro refere-se ao objetivo imediato do documento: angariar votos. A segunda diz respeito à função do documento em uma perspectiva mais ampla (função mediata): agitação e propaganda. (...) Assim, além de novas funções terem sido incluídas, as já existentes foram redefinidas, agregadas ou separadas. O tratamento diferenciado entre "objetivo" e "função" possibilitou a elaboração das séries documentais (LOPEZ, 1999, p. 82). 
De fato, uma das dificuldades da elaboração do Plano inclui o adequado manejo das funções e atividades do órgão produtor dos documentos. Segundo Lopes (1996, p. 92), no Brasil e em muitos países é comum o abismo entre "funções" e "atividades". A primeira é abstrata, definida na formalidade dos documentos de uma organização. A segunda é concreta; conhece-se uma organização pelo que efetivamente realiza. Tais entes de significado, se ausentes ou mal utilizados na classificação, vão atentar contra a qualidade do instrumento e obstruir o bom êxito da sua utilização. Ainda é grande o desconhecimento, por parte das pessoas que atuam nas organizações, acerca dos conceitos de "função" e "atividade". Segundo Silva e Severino (2009, p. 6), muitas vezes ninguém, e nem mesmo um pequeno grupo de pessoas, conhece profundamente todas as etapas do processo que realizam.

O corte abaixo, tomado do código 080.1 sob uma perspectiva hipotética das funções e atividades que deram causa aos documentos, se comparado com o do Conarq vai nos permitir visualizar com alguma clareza o quão árdua pode ser a tarefa de se elaborar um instrumento de classificação de documentos de arquivo. Contudo, para melhor compreensão deste corte, vejamos antes o conceito de "macrofunção".

Segundo Miranda (2006, p. 73), macrofunção é a competência organizacional que envolve o exercício de mais de uma função na estrutura organizacional, e a sua operação tem impacto significativo no modo como a organização funciona.

Macrofunção 080 - Gestão de Pessoal Militar

Função $\quad 080.1$ - Formulação da doutrina normativo/legal da gestão de pessoal militar Atividade

080.11 - Normatização de recrutamento e seleção

\section{Série Documental}

080.111 - Edital de concurso externo

080.112 - Edital de concurso interno

080.113 - Edital de reinclusão voluntária

080.12 - Elaboração de normatização para o funcionamento de sistemas de gestão do pessoal militar

080.121 - Sistema GEPES (Gestão de Pessoal Militar)

080.122 - Sistema Mapa da Força6

080.123 - Sistema de controle de movimentação militar

080.13 - Edição de convênios, contratos e ajustes relativos ao emprego de

pessoal militar

080.131 - Normas de auditoria de efetivos militares

080.132 - Normas de agregação e reversão de pessoal militar

080.14 - Planejamento de férias da Força (ou corporação)

080.141 - Calendário de férias da Força

080.142 - Legislação pertinente ao planejamento de férias da Força

080.15 - Normatização da aplicação de direitos e prerrogativas do pessoal militar

6 Mapa da Força é o documento elaborado semanalmente pelas unidades de polícia militar (quartéis) destinado a informar ao Estado-Maior da Corporação a situação da tropa em quantitativos, discriminando baixados, em férias, realizando curso, dentre outros. O Mapa da Força também discrimina o pessoal militar em termos de seu emprego (serviço interno, patrulhamento a pé, em motocicletas, aéreo, lacustre, rádio patrulhamento, etc.) e se há excedentes ou claros de pessoal, entre postos (oficiais) e graduações (praças). 
080.151 - Redução de interstício de Oficiais

080.152 - Redução de interstício de Praças

080.153 - Normas de aplicação da cota compulsória para Oficiais

080.154 - Normas de aplicação da cota compulsória para Praças

\section{Subsérie Documental}

080.155 - Normas de promoção de Oficiais

080.1551 - Ato de promoção de Oficial

080.156 - Normas de promoção de Praças

080.1561 - Ato de promoção de Praça

080.157 - Normas de condecorações

080.158 - Normas de avaliação do desempenho funcional do pessoal militar

080.159 - Normas de justiça e disciplina militar

Deste modo, pelo corte hipotético acima fica notório ao leitor o grau de desdobramentos e cognição que podem estar envolvidos no desenvolvimento de uma única linha do instrumento do Conarq, que no caso presente é o nível de código 080.1.

\section{TRAÇAR RUMOS SEM ENGESSAR (UMA ALUSÃO À QUANTIDADE DE NÍVEIS DE CLASSIFICAÇÃO)}

O número de níveis de classificação vai variar de acordo com o órgão ou entidade, em função de fatores como a complexidade de sua estrutura organizacional, as tecnologias utilizadas e a natureza das atividades desenvolvidas (ARQUIVO NACIONAL, 2006, p. 38).

A subclasse 080, proposta pelo Conarq, está desdobrada em quatro níveis. Partindo-se da premissa de que os quatro níveis primordiais correspondem à "macrofunção", "funções", "atividades" e às "séries documentais", nesta ordem, restaria ainda a possibilidade de se alocar a informação arquivística ao nível da "subfunção" e da "subsérie" para melhor identificar o contexto de criação dos documentos. Considera-se subfunção o agrupamento de atribuições afins, correspondendo cada subfunção a uma modalidade da respectiva função (BERNARDES, 2008, p.35).

Este quadro de Bernardes (2008, p. 41), exemplifica bem a idéia da subfunção:

Quadro 1 - Exemplo da subfunção no detalhamento da função e o respectivo ordenamento das atividades.

\begin{tabular}{|c|c|c|}
\hline Função & Subfunção & Atividades \\
\hline \multirow{7}{*}{$\begin{array}{l}\text { Promoção, difusão, } \\
\text { formação e } \\
\text { aperfeiçoamento cultural }\end{array}$} & \multirow{3}{*}{$\begin{array}{l}\text { Promoção e difusão } \\
\text { cultural }\end{array}$} & $\begin{array}{l}\text { Elaboração de obras para a difusão do conhecimento } \\
\text { cultural }\end{array}$ \\
\hline & & Realização de eventos culturais \\
\hline & & Realização de intercâmbio técnico-cultural \\
\hline & \multirow{4}{*}{$\begin{array}{l}\text { Formação e } \\
\text { aperfeiçoamento cultural }\end{array}$} & Realização de estudos e pesquisas \\
\hline & & Concessão de bolsa de estudo \\
\hline & & Realização de concursos culturais \\
\hline & & Realização de cursos \\
\hline
\end{tabular}


Fonte: Bernardes (2008, p. 41)

Poderá existir uma função sem subfunção, mas nunca uma função com apenas uma subfunção. O mesmo se aplica aos demais níveis da classificação, os quais devem ser totalmente exaustivos quanto ao nível de origem. O recorte a seguir (Quadro 2) obtido do instrumento de classificação de documentos de arquivo do Ministério público do Estado de São Paulo, nos ajuda a melhor entender este princípio.

Toda a complexidade que envolve o processo classificatório vai estar subjacente na notação. Daí, uma das funções primordiais do arquivista é permitir a síntese, ou seja, tornar simples o que é complexo.

Quadro 2 - Exemplo do desdobramento do nível "função" no contexto da classificação de documentos de arquivo.

\begin{tabular}{|c|c|c|c|c|}
\hline FUNÇÃO & $\begin{array}{l}\text { SUB- } \\
\text { FUN- } \\
\text { ÇÃ̃O }\end{array}$ & ATIVIDADES & & SÉRIE DOCUMENTAL \\
\hline \multirow{21}{*}{ 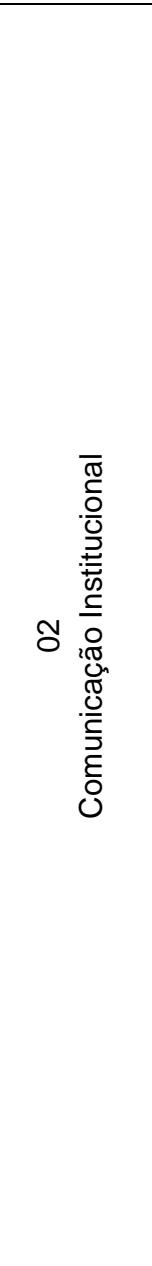 } & \multirow{9}{*}{ 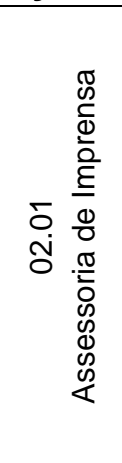 } & $\begin{array}{l}02.01 .01 \text { - Compilação de } \\
\text { notícias }\end{array}$ & 02.01 .01 .01 & Clipping \\
\hline & & \multirow{4}{*}{$\begin{array}{l}02.01 .02 \text { - Divulgação das } \\
\text { ações de governo }\end{array}$} & 02.01 .02 .01 & Artigo, nota e notícia \\
\hline & & & 02.01.02.02 & Credencial de jornalista \\
\hline & & & 02.01 .02 .03 & Release e sinopse \\
\hline & & & 02.01.02.04 & Site institucional \\
\hline & & $\begin{array}{l}02.01 .03 \text { - Editoração e } \\
\text { programação visual }\end{array}$ & 02.01 .03 .01 & $\begin{array}{l}\text { Diagramação para matérias de site } \\
\text { institucional }\end{array}$ \\
\hline & & \multirow{3}{*}{$\begin{array}{l}02.01 .04 \text { - Produção de } \\
\text { registros de imagem e som }\end{array}$} & 02.01 .04 .01 & Registro fotográfico \\
\hline & & & 02.01 .04 .02 & Registro sonoro \\
\hline & & & 02.01 .04 .03 & Vídeo institucional \\
\hline & \multirow{4}{*}{ 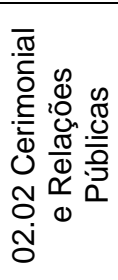 } & $\begin{array}{c}02.02 .01 \text { - Elaboração de } \\
\text { normas para recepções } \\
\text { oficiais }\end{array}$ & 02.02 .01 .01 & Norma do Cerimonial Público \\
\hline & & \multirow{3}{*}{ 02.02.02 - Apoio logístico } & 02.02.02.01 & Comunicado de instrução de serviço \\
\hline & & & 02.02.02.02 & Solicitação de contingente \\
\hline & & & 02.02 .02 .03 & Requisição de veículo \\
\hline & \multirow{8}{*}{ 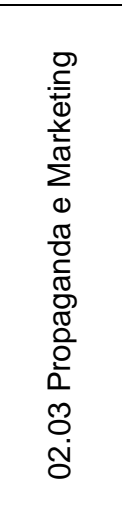 } & $\begin{array}{l}\text { 02.03.01 - Elaboração da } \\
\text { identidade visual }\end{array}$ & 02.03.01.01 & $\begin{array}{l}\text { Projeto executivo de identidade } \\
\text { visual }\end{array}$ \\
\hline & & \multirow{3}{*}{$\begin{array}{l}02.03 .02 \text { - Contratação de } \\
\text { agências de publicidade }\end{array}$} & 02.03.02.01 & Briefing de licitação \\
\hline & & & 02.03 .02 .02 & $\begin{array}{l}\text { Edital de contratação de agência de } \\
\text { publicidade }\end{array}$ \\
\hline & & & 02.03 .02 .03 & $\begin{array}{l}\text { Processo de contratação de agência } \\
\text { de publicidade }\end{array}$ \\
\hline & & \multirow{4}{*}{$\begin{array}{l}02.03 .03 \text { - Planejamento e } \\
\text { controle de atividades de } \\
\text { publicidade }\end{array}$} & 02.03 .03 .01 & Briefing de campanha \\
\hline & & & 02.03 .03 .02 & $\begin{array}{l}\text { Cadastro de despesas com } \\
\text { comunicação }\end{array}$ \\
\hline & & & 02.03 .03 .03 & Cadastro dos meios de comunicação \\
\hline & & & 02.03.03.04 & Pedido de campanha de publicidade \\
\hline
\end{tabular}

Fonte - http://www.mp.sp.gov.br/portal/page/portal/diretoria_geral2/dg_estudos_e_programas/ep_ gestao/ep_do cumental/doc_tabela_de_temporalidade 


\section{A CLASSIFICAÇÃO NO PAPEL DE REFERÊNCIA COMUM E COMPARTILHADA DE UM VOCABULÁRIO CONTROLADO}

A organização física dos documentos, ditada pelo código de classificação, embora feita de forma rigorosa, não será suficiente para garantir a recuperação da informação via emprego da informática se não houver consenso no vocabulário organizacional. É necessário lembrar que, além da notação numérica, a representação da informação também precisa ter nome.

Na elaboração de planos de classificação a preocupação com o controle de vocabulário deve estar presente na nomeação das funções, atividades, séries documentais e demais níveis de representação da informação, alcançando os documentos. A ISO 15489-1, referente à gestão de documentos de arquivo, é enfática quanto ao cuidado com a padronização de vocabulário em instrumentos de classificação:

A classificação de atividades funcionais (de negócios) atua como uma poderosa ferramenta para auxiliar a condução dos negócios e muitos dos processos envolvidos na gestão de documentos, incluindo: a) (...); b) assegurando que os documentos são nominados de uma forma (maneira) consistente (única) no tempo. (...) Sistemas de classificação e índices devem ser apoiados em vocabulário controlado que sejam adequados à complexidade dos registros de uma organização. Tais controles de vocabulário devem explicar as definições específicas da organização ou o uso de termos (Tradução nossa)7.

A este respeito, Smit e Kobashi (2003, p. 15) apontam que as rotinas atinentes à gestão dos arquivos correntes incluem, ou deveriam incluir, o devido cuidado com o controle de vocabulário ao se nomear, por exemplo, as funções, atividades e séries documentais no contexto dos instrumentos de gestão documental, os itens de listas de assuntos para emprego nas atividades de protocolo, bem como na hora de se atribuir título a formulários.

Uma vez que os processos organizacionais são os espaços de uso da informação, as funções e atividades são domínios específicos do labor arquivístico, cujo componente disciplinador fundamental é o controle de vocabulário. Ao se nomear uma função, por exemplo, há que se ter presente que esta se refere a mais de uma atividade. De igual modo, a frase que designa uma atividade deve contemplar a totalidade de suas séries documentais, e assim com todos os níveis de classificação do instrumento. Tomemos como exemplo o nível 089.1 do Conarq, onde é notório que o nome "Serviços de Escala" quase que se confunde com a tipologia a ser nele alocada (a Escala de Serviço), que por sinal se torna fato concreto e verificável pela TBTEx8.

\footnotetext{
7 The classification of business activities acts as a powerful tool to assist the conduct of business and in many of the processes involved in the management of records, including: a) (...), b) ensuring records are named in a consistent manner over time. (...) Classification systems and indexes may be supported by vocabulary controls that are suited to the complexity of the records of an organization. Such vocabulary controls should explain organization-specific definitions or usage of terms.

8 TBTEx (Tabela Básica de Temporalidade do Exército Brasileiro).
} 
A prática do uso de vocabulário "limitante", isto é, que restringe consideravelmente a capacidade dos diversos níveis de classificação em acolher séries documentais e tipologias "irmãs", vai impor ao classificador a tarefa de adequar alguns documentos remanescentes em outras funções ou atividades no instrumento.

Na Polícia Militar do Distrito Federal, por exemplo, onde toda a tropa figura na escala de serviço semanal, inclusive o pessoal do expediente interno, o nível 089.1 refere-se à atividade "Controle de Freqüência", com a série documental abarcando as seguintes tipologias:

- Escalas de serviço (incluindo a "campanha" do escalante);

- Formulário de autorização para troca de serviço;

- Formulário de controle de pernoite de pessoal militar9;

- Documentos de justificativa de falta/atraso ao serviço (inclui atestados de doação de sangue, guias de comparecimento a delegacias de polícia e a órgãos da Justiça, atestados médicos, dispensas do serviço, participação em curso, etc.);

- Mapa de controle do pessoal militar que concilia o horário de trabalho com os estudos;

- Livro de controle do serviço voluntário remunerado.

A organização interna da série se dá pela separação entre uma tipologia e outra, e estas ordenadas na seqüência crescente do número de identidade do policial militar, também chamado de matrícula do servidor.

Assim, do todo exposto, vislumbramos o plano de classificação também no papel de inventário fiel das tipologias praticadas pela organização (incluindo os formulários), e um vernáculo próprio a todas as esferas de negócio que esta venha a empreender. A informatização, que já faz parte da realidade arquivística das organizações em ampla escala, principalmente na produção dos documentos, e em sua busca e no controle de sua tramitação, é o melhor exemplo para ilustrar a questão aqui apontada. Chamamos à atenção uma possibilidade do caos se instalar, com relativa facilidade, em operações como a recuperação da informação: um currículo pode estar arquivado na "pasta de empregado", no "prontuário" ou no "dossiê funcional", ou na fase da produção, com o emprego de variadas tipologias para a mesma finalidade, dentre outros situações em que o "vilão" é a falta de uma linguagem comum.

Assim, o emprego crescente da informática nos arquivos tem tornado obrigatório o controle do vocabulário a ser utilizado. Smit e Kobashi (2003, p.15), mostram, com um exemplo simples do cotidiano, como o controle de vocabulário pode produzir confiança na informatização de arquivos:

Se alguns documentos (em suporte papel ou eletrônicos) são registrados sob a rubrica "solicitação de transporte", outros sob a rubrica "pedido de transporte" e ainda alguns sob a rubrica "requerimento de veículo", uma busca pelo termo "carro" não produzirá nenhuma resposta, e uma busca pelo termo "transporte" irá gerar uma resposta incompleta, pois outros documentos, que

9 Pernoite é o documento confeccionado pelos Comandantes de Subunidades, passado diariamente, que se destina à comprovação da presença das praças relacionadas para a revista do recolher (inspeção realizada antes do toque de silêncio). 
também deveriam ser encontrados, serão, literalmente, ignorados pelo sistema, como se não existissem.

\section{A SUBCLASSE 080: ATÉ QUANDO PODERÁ CONTINUAR SENDO A ÚLTIMA INCLUSÃO?}

Nossa indagação aponta para a limitada capacidade de expansão do plano de classificação proposto pelo Conarq. Tal instrumento foi criado com base no Código Decimal de Melvil Dewey, bibliotecário norte-americano que, em 1876, originariamente utilizou a idéia para organizar acervos bibliográficos. O principal fator de restrição deste método está no plano notacional, ou seja, somente nove dígitos podem ser utilizados para representar o primeiro nível da classificação.

A classe 000 - Administração Geral, onde são classificados os documentos referentes às atividades-meio, tem como subclasses:

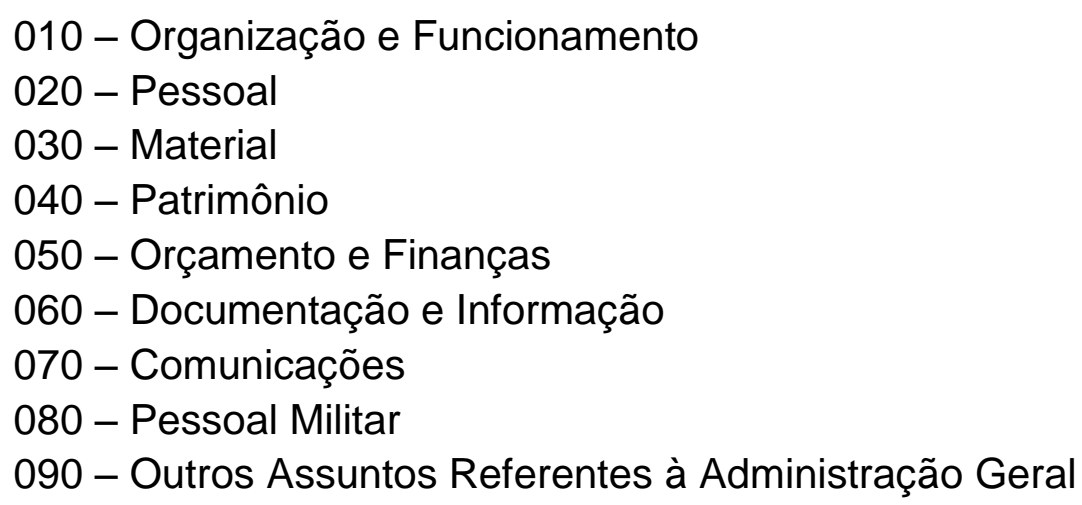

A classe 900 - Assuntos Diversos, refere-se aos documentos de caráter genérico relacionados às atividades-meio. $E$ as demais classes (100 a 800), se destinam aos assuntos relativos às atividades-fim, a cargo das peculiaridades de cada organização.

Assim, o plano de classificação do Conarq tornou-se exaurido na sua capacidade de alocar novas subclasses, pois está limitado a apenas nove, e todas já se encontram preenchidas. A classe 900 , desde que o instrumento seja atualizado periodicamente, não pode ser desviada de seu papel de "válvula de escape" para as miscelâneas e "outros" documentos. O mesmo se aplica aos últimos grupos de cada subclasse.

Isto se justifica pela indiscutível complexidade de um sistema de representação da informação, pois não há como conceber uma classificação total e tão exaustiva ao ponto de englobar toda a acumulação documental de uma organização. A classificação, enquanto uma representação da realidade, é como tal apenas uma aproximação. O emprego deste artifício se torna, portanto, um mal necessário. A este respeito, Sousa (2007, p. 115) alerta que é impositivo, entretanto, definir níveis de tolerância quanto à indeterminação, pois há que se ter limites para essa operação.

Uma vez que o problema está estabelecido, o que resta fazer? Obviamente que se busque uma nova metodologia, a qual permita a mais ampla capacidade 
possível de desdobramento dos níveis de classificação que se fizerem necessário.

Segundo o nosso modesto julgamento, atualmente o Sistema Bloco Numérico (SBN), de origem canadense, se apresenta como o mais viável para a solução do problema. O SBN foi desenvolvido no ano de 1987 por arquivistas da British Columbia University (ROSSI, 2005, p. 69). Pelo menos três motivos o qualificam como o mais adequado para a elaboração do instrumento classificatório de documentos: a) foi desenvolvido por arquivistas para uso em arquivos; b) à época da edição da primeira versão do plano de classificação do Conarq, em 1996, o Sistema Bloco Numérico já se encontrava na sua quarta edição e amplamente celebrado nos países considerados desenvolvidos (ROSSI, 2005, p. 70); e c) sua capacidade de expansão é praticamente ilimitada.

O SBN10 representa as funções, atividades e grandes temas em árvore hierárquica, de modo que estes sejam dispostos em níveis que são mais amplos no topo e mais específicos na base. Os seis blocos ou grupos temáticos, que representam as seis funções administrativas básicas de toda organização, seja ela de natureza pública ou privada, são o mais alto nível dessa classificação. Cada bloco recebe uma margem de código numérico, que não pode ser alterada.

- 1000-1999: Administração. Abarcam atos diretivos, legislação, comissões, comitês, cooperação com outras instituições, relatórios e estatísticas globais, delegações de autoridade, protocolo geral, e demais temas próprios à administração geral.

- 2000-2999: Patrimônio. Inclui a aquisição, construção, alteração e reparos de edificações próprias ou sob a responsabilidade da organização, bem como planos de prevenção contra incêndio, desastres, a aquisição de áreas de terra e demais ações relacionadas a bens imóveis e semoventes.

- 3000-3999: Materiais. Refere-se à aquisição, estocagem, distribuição, manutenção e demais assuntos relacionados à gestão do material de consumo e suprimentos.

- 4000-4999: Finanças. Cobre a formulação e acompanhamento do orçamento, a administração dos dispêndios e demais detalhes fiscais.

- 5000-5999: Recursos humanos. Inclui toda a documentação relacionada à gestão de pessoal, inclusive folha de pagamento, negociações trabalhistas e de planos de carreira, direitos e obrigações trabalhistas, dentre outros.

- 6000-6999: Serviços de informação. Bloco dedicado a todas as formas de gestão da informação organizacional, incluindo a informática, a comunicação social e marketing, telecomunicações, gestão de arquivos e bibliotecas, e demais serventias do tema.

As chamadas "primárias" são o próximo nível do SBN, onde cada bloco é dividido nas respectivas funções, atividades e temas gerais, por exemplo:

5050 - Pensionistas

$10 \begin{gathered}\text { Para obter mais informações sobre } \underset{\text { http://www.pws.gov.nt.ca/publications/Records/ ARCSTraining/module3.pdf }}{\circ} \text { Sistema Bloco } \\ \text { Numérico }\end{gathered}$ 


$$
\begin{aligned}
& 5250 \text { - Pessoal civil } \\
& 5450 \text { - Pessoal Militar }
\end{aligned}
$$

As primárias são arranjadas alfabeticamente. Cada primária, por sua vez, é subdividida nas chamadas "secundárias", sendo que cada uma delas obrigatoriamente terá duas em comum:

$$
\begin{aligned}
& 00 \text { - Política e procedimentos } \\
& 01 \text { - Geral }
\end{aligned}
$$

As secundárias não precisam ser arranjadas alfabeticamente, devendo ser numeradas $00,01,20,25,30, \ldots$, com saltos de cinco para permitir folgas para novas inclusões. Quando mais de oito a dez secundárias são encontradas na mesma primária deverá ser considerada a possibilidade de subdividir esta em duas primárias, visando à melhor praticidade do código.

As "terciárias" constituem o terceiro nível de classificação, designadas numericamente numa seqüência simples: $01,02,03, \ldots$, por exemplo:

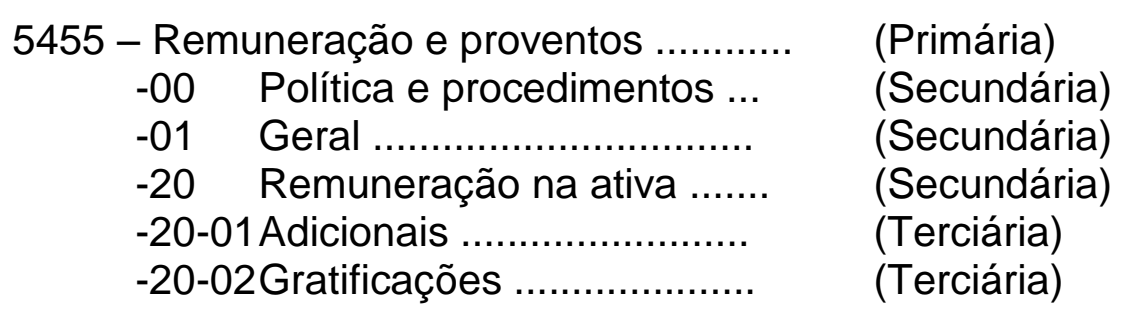

Assim, contando-se com o mais alto patamar da classificação - os blocos temáticos, o SBN está desdobrado em quatro níveis, ou seja, acarreta uma notação de fácil manejo, de mesmo tamanho da que está em vigor no Conarq.

Podemos, então, concluir este tópico à guisa do óbvio: a subclasse 080 do plano em vigor no serviço público brasileiro ocupou a última "vaga" que estava disponível no instrumento, sendo que, uma vez sob a configuração arquivística do SBN, poderia estar enquadrada no bloco "pessoal" sem causar o menor problema.

\section{CONSIDERAÇÕES FINAIS} este artigo:

Burke (1985, p. 4), soube traduzir bem o espírito que nos move ao escrever

No momento em que pegou pela primeira vez uma pedra ou um galho para usar como instrumento, o homem alterou irrevogavelmente o equilíbrio entre ele e seu meio... Enquanto o número desses instrumentos permaneceu pequeno, seus efeitos demoraram muito para causar mudanças. Mas à medida que aumentou, o mesmo aconteceu com seus efeitos. Quanto mais instrumentos, mais rápido é o ritmo das mudanças.

A utilidade do plano de classificação de documentos envolve todo um domínio de serventias que sempre estiveram agregados a ele de modo natural, 
enquanto infraestrutura de um modelo de governança documental, mas que, por razões diversas, podem não estar sendo colocadas em uso prático.

Como vocabulário controlado de funções, atividades e tipologias documentais de uma organização, por exemplo, levando em conta as terminologias propostas pelas áreas administrativa, jurídica, fiscal, etc., além das tradições da instituição, o instrumento de classificação cumpre o papel decisivo no desenvolvimento da complexidade dos elos organizacionais entre conhecimentos tácitos e explícitos. Afinal de contas, comunicar bem as idéias para os da mesma confraria, com o cuidado de não fazer disso uma linguagem elitista e hermética, principalmente no trato com o cliente, é qualidade indispensável a todo componente de um sistema de informação.

Sabemos que nem tudo pode ser traduzido, ou os americanos já teriam criado uma expressão inglesa para bossa-nova. Quando fizerem isso, iremos revidar e deixaremos de ouvir "jazz" e "blues", em troca de "música sincopada" e "azuis" (PERSONA, 2005).

É ponto pacífico os elementos fundamentais da classificação em arquivística, ou seja, seu domínio (o fundo de arquivo), os objetos de classificação (as séries documentais, e não documentos à parte), o critério funcional, (de modo a dar testemunho das funções e atividades que deram causa às séries documentais), e a notação (a mais simples possível). Urge, contudo, segundo até onde o nosso julgamento alcança, que as autoridades nacionais de arquivo se posicionem quanto ao elemento "estrutura" (se mono hierárquica ou se poli hierárquica - em facetas), de modo a escolher o método que melhor permita ao instrumento acomodar todas as séries documentais existentes na realidade organizacional considerada.

Entendemos que uma análise crítica satisfatória da classificação proposta pelo Conarq, a partir dos estudos disponíveis, não pode prescindir da fala de desaprovação dos usuários desta. A já citada pesquisa de Sousa e colaboradores (2006) apontam três não-conformidades do plano: a falta de clareza do instrumento, a possibilidade de classificar com mais de uma notação, levando a múltiplas interpretações, e a defasagem do Plano de Classificação, que não contempla todas as funções e atividades desenvolvidas pelos órgãos.

Neste sentido, o Sistema Bloco Numérico Canadense mostra-se uma opção alvissareira. Quando da elaboração da primeira proposta de um plano de classificação para a área meio do serviço público, acreditamos tenha ocorrido um lapso de assessoramento junto ao Conarq, pois, como já mencionado, já existia uma ferramenta testada e específica para aplicação em arquivos - o citado Sistema Bloco Numérico Canadense.

A despeito dos problemas aqui apontados em relação ao plano de classificação editado pelo Conarq, cumpre reconhecer sua capital relevância no contexto arquivístico nacional.

Até 1989, quando foi realizado o Cadastro Nacional de Arquivos Federais, não havia nenhuma política de arquivos, isto é, normas e procedimentos que orientassem a condução das atividades de arquivo na Administração Federal. $E$ no que se refere à 
classificação, a maioria dos arquivos não possuía um plano ou código de classificação de documentos. A pesquisa apontou uma mudança importante na situação arquivística dos órgãos públicos federais. Atualmente, mais da metade dos órgãos, isto é, 64\%, organizam seus arquivos a partir de um instrumento de classificação. (...) Em média, dois órgãos por ano adotam o Código de Classificação do Conarq (SOUSA et al., 2006, p. 11).

Cientes de que o desenvolvimento da disciplina arquivística, como em qualquer outra seara do conhecimento, se dá em uma espiral que se sustenta nas iniciativas imediatamente anteriores, ou seja, numa sucessão de estados onde 0 estado anterior é a causa do estado que o sucede, nossa alma almeja ter despertado um novo ânimo para aqueles dedicados à pesquisa e à prática da classificação da informação no âmbito da Arquivologia.

E assim somos nós arquivistas; profissionais com a consciência de que, ao longo da jornada, poderemos até concluir tarefas, mas nossa missão será, todavia, inacabada. Porque trabalhar com arquivos exige estudo, solidariedade, participação e um pouco de ousadia para enfrentar desafios e se tornar um agente de transformações.

\section{REFERÊNCIAS}

ARQUIVO NACIONAL (Brasil). Conarq. Câmara Técnica de Documentos Eletrônicos. Modelo de requerimentos para sistemas informatizados de gestão arquivística de documentos. 2006.

. Dicionário brasileiro de terminologia arquivística. Rio de Janeiro: Arquivo Nacional, 2005. 232p. Disponível em: <www.conarq.arquivonacional.gov.br /.../dicionrio_de_terminologia_arquivstica.pdf> Acesso em: 17 nov. 2009.

BERNARDES, leda Pimenta (Coord.). Manual de elaboração de planos de classificação e tabelas de temporalidade de documentos da administração pública do estado de São Paulo: atividades-fim. São Paulo: Arquivo Público do Estado de São Paulo, 2008. 107 p.

BURKE, James. Connections. Boston: Little, Brown, \& Co., 1985.

CONCEIÇÃO, Inaldo Nascimento. Padronização de instrumentos de classificação de documentos arquivísticos: uma proposta para as instituições federais de ensino superior e tecnológico do Ministério da Educação. In: CONGRESSO BRASILEIRO DE ARQUIVOLOGIA, 15., 2008, Goiânia. Anais... Goiânia: Associação dos Arquivistas Brasileiros; Associação de Arquivologia do Estado de Goiás, 2008. 16 p. Disponível em: <http://www.aag.org.br/anaisxvcba/conteudo/ resumos/comunicacoes_livres/inaldo.pdf > Acesso em: 20 out. 2009. 
CONSELHO INTERNACIONAL DE ARQUIVOS. ISDF: Norma Internacional para descrição de funções. Tradução de Vitor Manoel Marques da Fonseca. Rio de Janeiro: Arquivo Nacional, 2008.

GONÇALVES, Janice. Como classificar e ordenar documentos de arquivo. São Paulo: Arquivo do Estado. 1998. 37 p.

INDOLFO, Ana Celeste. O uso de normas arquivísticas no estado brasileiro: uma análise do poder executivo federal. 2008. Dissertação (Mestrado em Ciência da Informação) - Universidade Federal Fluminense e Instituto Brasileiro de Informação em Ciência e Tecnologia, Rio de Janeiro, 2008. Disponível em: $<$ http://ibict.phlnet.com.br/ anexos/anacelesteindolfo. pdf> Acesso em: 18 abr. 2011.

INTERNATIONAL STANDARDS ORGANIZATION. ISO 15489-1: information and documentation, records management, part 1: principes directeurs. Suisse: ISO, 2001. 19 p.

LOPES, Luis Carlos. A informação e os arquivos: teorias e práticas. Niterói: EDUFF; São Carlos: EDUFSCar, 1996.

LOPEZ, André Porto Ancona. Tipologia documental de partidos e associações políticas brasileiras. São Paulo: Loyola, 1999.

MIRANDA, Zenilton de Jesus Gayoso. Mapeamento de processos baseado em princípios da arquitetura da informação: uma perspectiva sistêmica. 2006. Dissertação (Especialização em Inteligência Organizacional e Competitiva) Universidade de Brasília, Brasília, 2006.

ORR, Stuart Anthony. Functions-based classification of records: is it functional? Archives \& Manuscripts Journal - Australian Society of Archivists. v. 34, n. 1, p. 29, may 2006. Disponível em: <http://www.irma.is/Portals/6/frodleikur/Orr_Functional _Classification.pdf> Acesso em: 20 nov. 2009.

PERSONA, Mario. Up to date com a linguagem corporativa. Disponível em: <http://www.scrittaonline.com.br/artigos/up-to-date-com-a-linguagem-corporativa> Acesso em: 18 abr. 2011.

RIBEIRO, Fernanda. Indexação e control de autoridade em arquivos. Porto: câmara Municipal do Porto/Arquivo Histórico, 1996.

RODRIGUES, Georgete Medleg. A representação da informação em arquivística: uma abordagem a partir da perspectiva da Norma Internacional de Descrição Arquivística. In: RODRIGUES, Georgete Medleg; LOPES, Ilza Leite (Org.). Organização e representação do conhecimento na perspectiva da Ciência da Informação. Brasília: Thesaurus, 2003.

ROSSI, Elena Aga. Strumenti e materiali di qualità per l'informatizzazione della gestione documentale. Roma: Scuola Superiore della Pubblica Amministrazione, 
2005. 191 p. Disponível em: <www.sspa.it/share/progetti/51/51_Strumenti.pdf> Acesso em: 22 nov. 2009.

SCHELLENBERG, T. R. Arquivos modernos: princípios e técnicas. Rio de Janeiro: FGV, 2005.

SILVA, Devanildo Damião da; SEVERINO, Patrícia. Desenvolvendo a gestão do conhecimento sob o prisma do mapeamento de processos: proposta de uma metodologia. Biblioteca Terraforum Consultores. Disponível em: <http://www. terraforum.com.br/biblioteca/Documents/libdoc00000043v002Desenvolvendo\%20 a\%20Gestao\%20do\%20Conhecimento\%20sob.pdf > Acesso em: 23 out. 2009.

SMIT, Johanna Wilhelmina; KOBASHI, Nair Yumico. Como elaborar vocabulário controlado para aplicação em arquivos. São Paulo: Arquivo do Estado; Imprensa Oficial, 2003. 56 p. (Projeto Como Fazer, v.10).

SOUSA, Renato et al. O uso do código de classificação de documentos de arquivo do conselho nacional de arquivos. Arquivistica.net, Rio de Janeiro, v. 2, n. 2, ago./dez. 2006. p.19-37. Disponível em: <http://www.arquivistica.net/ojs/ viewarticle.php?id=95\&layout=abstract> Acesso em: 21 set. 2009.

SOUSA, Renato Tarciso Barbosa. Classificação de documentos arquivísticos: trajetória de um conceito. Arquivistica.net, Rio de Janeiro, v. 2, n. 2, p. 120-142, ago./dez. 2006. Disponível em: <http://www.arquivistica.net/ojs/viewarticle.php? id=64\&layout=abstract $>$ Acesso em: 19 out. 2009.

A classificação como função matricial do que fazer arquivístico. In: SANTOS, Vanderlei Batista dos. (Org.). Arquivística: temas contemporâneos. Distrito Federal: Senac, 2007. p. 87-157.

A informação orgânica arquivística. Boletim da Rede de Arquivos do Ministério da Ciência e Tecnologia, Brasília, v. 2, n. 1, p. 27-31, jan./jun.2009. Disponível em: <www.siga.arquivonacional.gov.br/media/boletins_mct/ba012009 .pdf> Acesso em: 07 mar. 2011.

THOMASSEM, Theo. Uma primeira introdução à arquivologia. Revista Arquivo \& Administração, Rio de Janeiro, v. 5, n. 1, p. 5-16, 2006.

\section{Title}

The Filing Plan Guidelines from the National Archives Council: a critical analysis

\section{Abstract}

Based on the filing plan proposed by the National Archives Council (Conarq), and taking as analysis section the subclass 080 - Military Personnel, this study provides an overview of the inaccuracies and limitations of the instrument and at the same time suggests new perspectives in implementing the classification as an archival function. The paper also 
gives a glimpse about the in applying the classification scheme proposed on this topic and suggests a filing plan methodology different from the one which is currently used by Conarq.

\section{Key-Words}

Information retrieval. Filing plan. Records management. Document Management.

\section{Titulo}

El Plan de Clasificación de los Documentos del Consejo Nacional de Archivos: un análisis crítico

\section{Resumen}

En el artículo, se presenta una visión general de las imprecisiones y las limitaciones de el plan de clasificación de documentos propuesto por CONARQ utilizando como análisis un corte de subclase 080 - Personal Militar, al tiempo que sugiere nuevas perspectivas en la aplicación de la clasificación mientras que una función de archivo. El texto también da una idea de los retos de razonamiento involucrados en la práctica de la temática y sugiere otra metodología de clasificación, diferente de lo que ahora es utilizado por CONARQ.

\section{Palabras clave}

Recuperación de la información, Plan de organización de documentos, Tratamiento archivístico.

Recebido em: 16/03/2011

Aceito em: 11/05/2011 